\title{
Visita à criança hospitalizada em terapia intensiva: vivências de irmãos reveladas por meio do brinquedo terapêutico dramático
}

\author{
Visit to a hospitalized child in intensive care: sibling's experiences revealed by dramatic therapeutic play \\ Visita al niño hospitalizado en terapia intensiva: vivencias de hermanos revelado por el juego \\ terapéutico dramático
}

1. Universidade Metodista de Piracicaba, Curso de Enfermagem. Piracicaba, SP, Brasil.

2. Universidade Estadual de Campinas, Faculdade de Enfermagem. Campinas, SP, Brasil.
Autor Correspondente: Luciana de Lione Melo. E-mail: lulione@unicamp.br

\section{Recebido em 06/04/2021.}

Aprovado em 12/08/2021.

DOI:https://doi.org/10.1590/2177-9465-EAN-2021-0088

\section{Resumo}

Objetivo: compreender, por meio do brinquedo terapêutico dramático, o significado, para o irmão, de visitar a criança hospitalizada em terapia intensiva. Método: pesquisa qualitativa, modalidade fenomenológica, que utilizou o brinquedo terapêutico dramático para acessar às experiências dos irmãos. Foi realizada em Unidade de Terapia Intensiva Pediátrica do interior do estado de São Paulo, Brasil. Participaram das sessões de brinquedo terapêutico 11 irmãos menores de 10 anos, as quais foram analisadas à luz da Teoria do Amadurecimento. Resultados: os irmãos, tendo um lugar para brincar, dramatizaram situações, anteriormente, vividas, de seu cotidiano e da visita à criança hospitalizada. Ao viver, criativamente, revelaram que brincar é fazer a integração das experiências do "eu", favorecendo o continuar a ser diante da situação vivida. Conclusões e implicações para a prática: 0 Brinquedo Terapêutico Dramático compreendido à luz de um referencial teórico possibilitou que o irmão significasse a visita como uma experiência de integração do "eu", revelando emoções, desejos e preferências do cotidiano. Nesse sentido, o cuidado ao irmão da criança hospitalizada define-se pela oferta do brincar livre, para que ele demonstre o sentimento de continuar a ser em suas interações com o mundo, no qual o contexto hospitalar tornou parte da realidade.

Palavras-chave: Enfermagem Pediátrica; Irmãos; Jogos e Brinquedos; Unidades de Terapia Intensiva Pediátrica; Visitas a Pacientes.

\section{Abstract}

Objective: To understand, by means of the dramatic therapeutic play, the meaning, to the sibling, of visiting a hospitalized child in Pediatric Intensive Care. Method: Qualitative research, phenomenology modality, which used the dramatic therapeutic play to understand the sibling's experience. The research was carried out at a Pediatric Intensive Care Unit of a hospital located in one of São Paulo's inland cities, Brazil. Eleven siblings younger than 10 years of age participated in therapeutic play sessions that were analyzed in light of the Theory of the Maturational Processes. Results: Having a place to play, the siblings dramatized situations that they had previously experienced in their daily life and in the visit to the hospitalized child. Living creatively, they revealed that playing means making the integration of the experiences of the "self", favoring the feeling of continuing to be, despite the experienced situation. Conclusions and implications for practice: The Dramatic Therapeutic Play understood in the light of a theoretical framework made it possible for the brother to signify the visit as an experience of integration of the "self", revealing emotions, desires and everyday preferences. In this sense, the care of the hospitalized child's sibling is defined by play freely, so that he can demonstrate his feeling of continuing to be in his interactions with the world, in which the hospital context has become part of reality.

Keywords: Pediatric Nursing; Siblings; Play and Playthings; Intensive Care Units, Pediatric; Visitors to Patients.

\section{Resumen}

Objeto: Comprender por medio del juego terapéutico dramático el significado, para el hermano, de la visita al niño hospitalizado en Terapia Intensiva Pediátrica. Método: Investigación cualitativa, modalidad fenomenológica, que utilizó el juego terapéutico dramático para comprender la experiencia del hermano. Se realizó en Unidad de Terapia Intensiva Pediátrica del interior del Estado de São Paulo, Brasil. Participaron de las sesiones de juego terapéutico 11 hermanos con menos de 10 años, quienes fueron analizados a la luz de la Teoría de la Maduración. Resultados: Los hermanos, al tener un lugar para jugar, dramatizaron situaciones anteriormente vividas, de su cotidiano y de la visita al niño hospitalizado. Al vivir de forma creativa, revelaron que jugar es permitir la integración de las experiencias del "yo", lo que favorece el concepto de seguir siendo, ante la situación vivida. Conclusiones e implicaciones para la práctica: El Juego Terapéutico Dramático comprendido a la luz de un referencial teórico hizo posible que el hermano entendiera la visita como una experiencia de integración del "yo", revelando emociones, deseos y preferencias cotidianas. En este sentido, el cuidado del hermano del niño hospitalizado se define por la oferta de juego libre, para que pueda demostrar su sentimiento de seguir siendo en sus interacciones con el mundo, en el que el contexto hospitalario se ha convertido en parte de la realidad.

Palabras clave: Enfermería Pediátrica; Hermanos; Juego e Implementos de Juego; Unidades de Cuidado Intensivo Pediátrico; Visitas a Pacientes. 


\section{INTRODUÇÃO}

Visitas em unidades de terapia intensiva costumam ser restritas e com horários pré-estabelecidos, sendo incomum a entrada de crianças menores de 12 anos. Trata-se de uma questão bastante controversa, embora os avanços científicos das últimas décadas evidenciem sua importância para a recuperação dos pacientes ${ }^{1,2}$

As restrições impostas às visitas baseiam-se no risco de infecção aos pacientes e aos visitantes, além da possibilidade de trauma emocional em função do ambiente hostil e desconhecido. A falta de espaço físico e de recursos humanos capacitados também são justificativas para impedir visitantes nessas unidades ${ }^{3}$.

Todavia, desde a década de 1980, esses aspectos têm sido refutados por estudiosos que defendem a visita aberta e a presença da família durante a hospitalização de crianças, inclusive com legislação vigente $e^{4,5}$.

Limitar ou impedir a visita em unidades intensivas pode causar impacto negativo sobre a família, que também é afetada pela situação de doença e por todos os aspectos decorrentes dela, o que pode provocar sentimentos negativos, em especial nos irmãos da criança doente ${ }^{6}$.

Com frequência, os irmãos são mantidos à margem da situação de adoecimento de um membro da família, em uma tentativa de poupá-los. Os pais, muitas vezes, omitem informações e/ou os afastam do cuidado e do apoio à criança doente ${ }^{4,6}$. Entretanto, isso caminha na contramão de preservar a saúde emocional, pois essa conduta não os impede de serem atingidos por tudo o que ocorre à sua volta 7 .

Pesquisas sobre visitas de irmãos às crianças hospitalizadas a partir da perspectiva dos próprios irmãos são escassas. Contudo, estudo que buscou refletir sobre a visita de crianças a adultos hospitalizados em unidade intensiva, revelou que a visita favorece o processo de luto da criança, embora os profissionais de saúde nem sempre tenham estratégias que subsidiem essa prática ${ }^{8}$.

Ouvir os irmãos, responder às suas perguntas e dúvidas quanto à criança hospitalizada, aproximando-os da situação vivida por meio da visita, se esse for o seu desejo, é importante, podendo diminuir o estresse da separação familiar, resgatando o sentimento de pertença, que pode estar fragilizado e aliviando fantasias relacionadas ao adoecimento favorecendo, ainda, a construção da realidade, pois, geralmente, a imaginação sobre a condição da criança doente pode não representar o fato ${ }^{4,6}$.

Para isso, o profissional necessita ter conhecimento e estar preparado para acolher os irmãos. Entre os recursos disponíveis para a comunicação com eles está o brincar, com destaque para o Brinquedo Terapêutico (BT). Uma das modalidades de BT, a dramática, possibilita a descarga emocional, pois, brincando, a criança exterioriza sentimentos e vivências, buscando compreendêlas e permitindo, também, sua compreensão pelo enfermeiro ${ }^{9}$.

Considerando que o BT é uma tecnologia de cuidado regulamentada no exercício profissional da equipe de enfermagem ${ }^{9-11}$ e que o BTD é utilizado em estudos com crianças para revelar experiências diversas, como hospitalização, adoecimento e privação materna ${ }^{12-14}$, dentre outras, empregá-lo com irmãos de crianças hospitalizadas para acessar às experiências de visita em unidade intensiva, poderá trazer elementos relevantes para ampliar as discussões sobre visitação de crianças em hospitais.

Assim, o objetivo deste estudo é compreender, por meio do brinquedo terapêutico dramático, o significado, para o irmão, de visitar a criança hospitalizada em terapia intensiva.

\section{MÉTODO}

Pesquisa qualitativa, de modalidade fenomenológica. Estudos dessa natureza têm como essência compreender a experiência vivida e o significado dado a ela, a partir daquele que a vivencia, considerando sua singularidade, sem a formulação de hipóteses ou inferências. Adotou-se a Análise da Estrutura do Fenômeno Situado como referencial metodológico ${ }^{15}$ e a Teoria do Amadurecimento de D.W. Winnicott ${ }^{16-21}$, como referencial teórico.

Fenomenologia é a disciplina que estuda a descrição do que aparece, daquilo que surge para a consciência e se mostra, se manifesta, se desvela ao indivíduo que interroga. Trata-se de uma ciência descritiva, rigorosa, concreta, que permite mostrar e explicitar o ser nele mesmo, numa preocupação com a essência do vivido ${ }^{15}$.

A Análise da Estrutura do Fenômeno Situado investiga, de forma direta, as vivências humanas, buscando construir conhecimento voltado à compreensão da dinâmica das significações, sem se prender às explicações causais ou às generalizações. A pretensão é conhecer o indivíduo e entender o processo pelo qual ele constrói e descreve seus significados. À medida que descreve e interpreta de forma ampla os fenômenos humanos, decodificando o complexo sistema de significados, o pesquisador vai criando condições para uma reflexão que visa a compreensão do fenômeno ${ }^{15}$.

Quanto a escolha pela Teoria do Amadurecimento de Winnicott, essa permite responder à interrogação desse estudo, na medida em que define a saúde do indivíduo, a partir do seu processo de desenvolvimento emocional ${ }^{16,18}$. Ela é fundamentada em dois princípios básicos: a tendência inata ao amadurecimento, a qual oferece os subsídios para a leitura da experiência vivida; e a existência contínua de um ambiente facilitador, que, por meio do cuidado suficientemente bom, fomenta a interpretação das relações que conectam a experiência dos seres humanos ${ }^{17}$.

$\mathrm{Na}$ jornada do amadurecimento, há capacidades a serem conquistadas e experiências a serem integradas, o que depende do processo de constituição da realidade, do qual faz parte o brincar ${ }^{20}$. Brincar é uma atividade sofisticada, por meio do qual a criança pode converter seus impulsos em atividades simbólicas e criativas, tendo condições de lidar com as ansiedades advindas das experiências vividas e, também, permite desvelar o processo da construção de sua subjetividade, a partir das suas relações com o outro e com o mundo ${ }^{21}$.

O estudo foi desenvolvido em uma Unidade de Terapia Intensiva (UTI) Pediátrica de um hospital filantrópico de grande porte, do interior do estado de São Paulo, com um total de sete leitos, onde a equipe multiprofissional assiste crianças graves, com idade entre 29 dias e 14 anos. 
As visitas às crianças são diárias, em dois períodos, com a entrada de duas pessoas maiores de 12 anos, sem revezamento. A visitação por menores é uma excepcionalidade, limitada aos irmãos, apenas em resposta à solicitação dos pais ou da criança hospitalizada, mediante autorização do enfermeiro.

Os critérios de inclusão foram irmãos entre 3 e 10 anos, por ser a faixa etária recomendada para a utilização do $\mathrm{BT}^{9,22}$, interesse do responsável e possibilidade de trazer o irmão para visitar à criança hospitalizada e, ainda, que não tivesse experiência de visita anterior. Foram critérios de exclusão, irmãos com algum problema de saúde cuja visita fosse contraindicada pela equipe multiprofissional e que já conhecessem o ambiente de unidade intensiva.

Desse modo, 12 famílias foram abordadas e informadas sobre o objetivo do estudo e de que modo seria a participação dos filhos. Dessas, uma recusou-se por acreditar que a visita à criança hospitalizada seria prejudicial à saúde do irmão. Outras duas famílias, embora tenham demonstrado interesse, não puderam trazer os irmãos ao hospital, sendo uma por dificuldades financeiras e, a outra, por transferência da criança hospitalizada. As que concordaram, assinaram o Termo de Consentimento Livre e Esclarecido (TCLE) permanecendo com uma cópia, sendo agendado dia e hora para que o irmão visitasse à criança hospitalizada.

Antes da visita, a pesquisadora principal, vestida com roupas comuns e jaleco, abordava o irmão na sala de recepção da Unidade, onde há um sofá e mesas/cadeiras infantis. Por meio do Termo de Assentimento (TA), descrição lúdica elaborada especialmente para esse fim, o irmão era convidado a brincar após visitar a criança hospitalizada.

Todos os irmãos cujas famílias assinaram o TCLE, aceitaram participar da sessão de BTD. Assim, participaram do estudo 11 irmãos de nove crianças hospitalizadas. $O$ quadro a seguir (Quadro 1) apresenta os participantes do estudo. A coleta de dados ocorreu no período de dezembro de 2017 a janeiro de 2019 .

Foram realizadas 11 sessões de BTD iniciadas com a questão norteadora: "Vamos brincar de uma criança que visitou seu irmão na UTI Pediátrica?" Nesse momento, foi acordado o tempo da sessão mostrando os ponteiros do relógio para indicar o tempo previsto, mas explicado que a brincadeira poderia ser interrompida a qualquer momento.

O tempo da sessão de BTD pode variar entre 15 e 45 minutos $^{9}$, contudo a criança pode solicitar mais algum tempo para concluir a brincadeira, o que aconteceu com quatro irmãos. Dessa forma, o tempo de cada sessão variou entre 15 e 59 minutos.

A seleção dos brinquedos seguiu as recomendações da literatura ${ }^{9,22}$, sendo disponibilizados numa caixa plástica, bonecos representando a família, profissionais de saúde, animais e objetos domésticos e do cotidiano, como alimentos variados, carrinhos, ferramentas e materiais hospitalares (seringa, agulha, frascos de medicamento, termômetro, eletrodos, estetoscópio, máscara, luva, entre outros). Ainda, lápis de cor e bloco de papel.

Os registros ocorreram em áudio digital e por meio de um diário de campo, onde foram descritas impressões gerais e percepções acerca do comportamento dos irmãos, auxiliando para o esclarecimento do momento da brincadeira, subsidiando a análise do brincar. Considerando o princípio da pesquisa fenomenológica de que o fenômeno a ser desvelado acontece no momento das manifestações dos participantes e não posteriormente ${ }^{23}$, foi optado por não filmar as sessões de BTD.

A transcrição dos áudios ocorreu logo após o término de cada sessão de BTD, sendo que as sessões foram encerradas quando os discursos mostraram consistência, isto é, quando atingiu a saturação teórica, o que significa que a partir de um processo analítico constante, os pesquisadores observaram que novos elementos deixaram de surgir nas brincadeiras ${ }^{24}$.

A análise seguiu os passos preconizados pela Análise da Estrutura do Fenômeno Situado: leitura global do conteúdo total das sessões junto as informações do diário de campo, de forma a apreender sua configuração global; releitura atenta, de modo a identificar as afirmações significativas (unidades de significados); busca de convergências e divergências para construção das categorias temáticas e elaboração da síntese descritiva ${ }^{15}$ realizada à luz teoria do amadurecimento de Winnicott ${ }^{16-21}$.

Garantindo a privacidade dos participantes e a proteção de sua identidade, optou-se por utilizar nomes de personagens de animação infantil, escolhidos pela pesquisadora principal. $O$ estudo seguiu as recomendações estabelecidas pela Resolução ํo 466, de 12 de dezembro de 2012, e foi aprovado pelo Comitê de Ética em Pesquisa da Universidade Estadual de Campinas sob o parecer no 2.652.332 e CAAE no 65571417.1.0000.5404 de 14 de maio de 2018.

\section{RESULTADOS}

Ao compreender a experiência dos irmãos que visitaram às crianças hospitalizadas na unidade intensiva, emergiram duas categorias: "Tendo um lugar para brincar" " "Vivendo criativamente: brincar é fazer". Essas categorias serão apresentadas a seguir e ilustradas por meio dos discursos dos irmãos extraídos durante a sessão de BTD, seguidos pelo nome fictício e idade.

\section{Tendo um lugar para brincar}

Os irmãos reconheceram o ambiente de brincadeira como suficientemente bom capaz de receber seu brincar. Assim, aceitando o convite para brincar, exploraram o ambiente procurando elementos para a brincadeira e reconhecendo objetos disponíveis para brincar.

Ao selecionar brinquedos preferiram, inicialmente, aqueles que aludiam à experiência da visita, mas também se interessaram por outros elementos da caixa.

Bart explora a caixa. Agora preciso achar um visitante! Aqui! Achei! Um bebezinho! Aqui... dentro. [Colocando o boneco-bebê na cama do cenário da UTI Pediátrica; volta a explorar] Achei! [encontrando a coberta da cama] Vou colocar na cama... esse aqui... desse jeito... [Cantarolando coloca a coberta sobre o bebê que está na cama; volta a explorar] (Bart, 9 anos) 
Quadro 1. Irmãos participantes do estudo. Campinas, 2019.

\begin{tabular}{|c|c|c|c|}
\hline $\begin{array}{l}\text { Irmão visitante, } \\
\text { Idade }\end{array}$ & $\begin{array}{l}\text { Criança hospitalizada, } \\
\text { idade }\end{array}$ & $\begin{array}{c}\text { Diagnóstico (Dias UTI Pediátrica); condição geral, } \\
\text { dispositivos }\end{array}$ & $\begin{array}{l}\text { Duração BT } \\
\text { Dramático }\end{array}$ \\
\hline Jorel, 8 anos & $\begin{array}{l}\text { Irmão do Jorel, } 4 \\
\text { meses }\end{array}$ & $\begin{array}{l}\text { Miocardiopatia + Pneumonia (3) } \\
\text { Bom estado geral, acordado, interage com a } \\
\text { família; oxigenioterapia (cateter nasal), soroterapia, } \\
\text { monitorização não invasiva }\end{array}$ & 37 minutos \\
\hline Peppa Pig, 3 anos & George Pig, 5 meses & $\begin{array}{l}\text { Bronquiolite (8) } \\
\text { Bom estado geral, acordado, interage com a família; } \\
\text { oxigenioterapia (máscara facial), soroterapia, } \\
\text { monitorização não invasiva }\end{array}$ & 37 minutos \\
\hline Sitka, 10 anos & Denahi, 8 anos & $\begin{array}{l}\text { Fibrose cística (23) } \\
\text { Bom estado geral, acordado, comunicativo; em } \\
\text { isolamento protetor, soroterapia, monitorização não } \\
\text { invasiva }\end{array}$ & 15 minutos \\
\hline Tommy, 9 anos & Dil, 3 meses & $\begin{array}{l}\text { Pneumonia (1) } \\
\text { Bom estado geral, acordado, interage com a família; } \\
\text { oxigenioterapia (máscara facial), soroterapia, } \\
\text { monitorização não invasiva }\end{array}$ & 38 minutos \\
\hline Bart, 9 anos & Marggie, 3 anos & $\begin{array}{l}\text { Pneumonia + Derrame Pleural ( } 21 \text { ) } \\
\text { Bom estado geral, interage com a família; oxigenioterapia } \\
\text { (máscara facial), soroterapia, dreno de tórax, } \\
\text { monitorização não invasiva }\end{array}$ & 27 minutos \\
\hline $\begin{array}{l}\text { Smurfinha, } 9 \\
\text { anos }\end{array}$ & Neném Smurf, 9 meses & $\begin{array}{l}\text { Pneumonia (15) } \\
\text { Bom estado geral, ativo, interage com a família; } \\
\text { oxigenioterapia (máscara facial), soroterapia, } \\
\text { monitorização não invasiva }\end{array}$ & 17 minutos \\
\hline Gumball, 9 anos & & Síndrome Genética (9) & \\
\hline Anais, 5 anos & Darwin, 9 anos & $\begin{array}{l}\text { Em cuidados paliativos, estável, interage com a } \\
\text { família; intubado, ventilação mecânica, soroterapia, } \\
\text { monitorização não invasiva }\end{array}$ & 46 minutos \\
\hline Charlie, 7 anos & & Pneumonia (6) & \\
\hline Lola, 4 anos & Bebê, 2 meses & $\begin{array}{l}\text { Bom estado geral, ativo, interage com a família; } \\
\text { oxigenioterapia (máscara facial), soroterapia, } \\
\text { monitorização não invasiva }\end{array}$ & 48 minutos \\
\hline Elroy, 3 anos & Judy, 9 anos & $\begin{array}{l}\text { Pneumonia + Derrame Pleural (27) } \\
\text { Bom estado geral, ativa, interage com a família; } \\
\text { oxigenioterapia (máscara facial), soroterapia, dreno de } \\
\text { tórax, monitorização não invasiva }\end{array}$ & 50 minutos \\
\hline
\end{tabular}

Fonte: Dados da pesquisa, 2019.

Smurfinha encontra pratos coloridos e os dispõe um à sua frente e outro à frente da pesquisadora. Encontra um ovo frito. Ovinho. Coloca no prato [retira da caixa outros utensílios domésticos - panelas, talheres, copos, agrupando-os por similaridades]. (Smurfinha, 9 anos)

Peppa Pig explora a caixa; encontra um bloco de papel e um estojo com lápis de cor. 'Qué quevê' (quero escrever) aqui... [pega um lápis e faz um rabisco no papel] (Peppa Pig, 3 anos)
Observou-se também interesse dos irmãos por determinado brinquedo ao reconhecerem a possibilidade de realizar outra função.

Tommy retira da caixa uma furadeira. Uma arma! Tá tá tá... [simula tiros] Mas, estranho... [olhando para sua ponta] a ponta parece de cola... é arma de cola? (Tommy, 9 anos)

Os irmãos reconheceram os objetos disponibilizados, o que se mostrou quando nomearam brinquedos, objetos e personagens e quando brincaram simulando o seu uso. 
Lola explora a caixa e retira dela o estetoscópio: Vamos ouvir o coração da tia $P$ (nome da pesquisadora) [apoia o estetoscópio na bancada e retira da caixa um par de luvas] Coloca a luva aqui pra mim? [estica as mãos para $P$ e entrega as luvas]

$\mathrm{P}:$ Onde que você quer que eu coloque a luva?

Lola: Na mão! Nessa... [estica uma das mãos] Agora nessa aqui... [estica a outra] (Lola, 4 anos)

Ao encontrar insumos médico-hospitalares, os reconheceu e declarou que não seriam para brincar.

Charlie encontra um kit medicação via oral na caixa. Isso não é de brincar! [...] [Explora a caixa e encontra seringas, ampola de SF0,9\%. Pega-as e coloca sobre a bancada.] Tem tanta coisa de médico aqui... Vocês não usam essas coisas?

$\mathrm{P}:$ A gente não usa?

Charlie: Não... porque tá aqui dentro da caixa... então... aqui dentro com os brinquedos. Mas... mas eles funcionam?

\section{$\mathrm{P}:$ Funcionam?}

Charlie: Sim! [empurrando e puxando o êmbolo da seringa] (Charlie, 7 anos)

Os irmãos relacionaram os brinquedos e personagens da caixa à experiência da visita, como exemplo associam o boneco de branco à enfermeira pesquisadora.

Bart explora a caixa; encontra o boneco representativo da pesquisadora. Ó, a enfermeira... [mostra à pesquisadora um boneco vestido de branco] Tá aqui... [arrumando o boneco no cenário da UTI Pediátrica] O que mais combina com você vai... Branco... sabe... por quê? 'cê tá' de branco! (Bart, 9 anos)

\section{Vivendo criativamente: brincar é fazer}

Trazendo à brincadeira elementos alusivos ao seu cotidiano, às experiências e à realidade vivida, os usaram, dramatizando lembranças antigas e a situação da visita; recriando, destruindo e reconstruindo o ambiente da terapia intensiva. Ainda, mostraram perceber sobre si, ter um olhar para o outro e agir conforme sua vontade. Os brinquedos mobilizaram lembranças de situações, anteriormente, vividas, e foram dramatizadas na brincadeira.

Lola pega um cachorro da Patrulha Canina que está sobre a bancada: Olha! 'Vamo cortá' a Zuma! Cortar a Zuma! Vou cortar a Zuma! Eu vou cortar o pé da Zuma. A Zuma vai ficar dodói! [cantarolando] Porque ela tinha que tirar uns pontos... Igual o Charlie fez aqui. [tocando a testa do irmão, onde havia uma discreta cicatriz] Pin! Primeiro ele colocou na testa. [coloca uma compressa de gaze na testa do irmão e a mantém com o apoio da tesoura] E tirou, né? E eu chorei!

Charlie: Eu coloquei na testa a tesoura? As 'enfermeira'!

Lola: As 'enfermeira' colocou... e daí eu vi o Charlie, e aí eu chorei... (Charlie, 7 anos; Lola, 4 anos)

Eles também dramatizaram a experiência de visitar a criança hospitalizada.

Sitka abre a caixa e encontra os objetos que remetem à experiência da visita, pega-os e coloca-os sobre a bancada. Eu tenho que demonstrar como eu entrei lá? Eu vou demonstrar como que eu cheguei. Como eu fui ver meu irmão. [pega um boneco para representá-lo] Eu cheguei aqui, aí eu lavei a mão, entrei lá. Meu pai ficou aqui, com a minha mãe. [mostra no cenário onde os pais ficaram dentro da UTI Pediátrica] Cheguei, abracei o Denahi, falei que eu estava com saudade; ele falou que também estava. Depois, ele falou se eu queria desenhar. Aí nós ficamos desenhando. Desenhamos e aí depois você chegou. (Sitka, 10 anos)

A capacidade de brincar dos irmãos permitiu recriar o cenário da UTI Pediátrica, inserindo nesse ambiente, novos elementos.

Bart explora a caixa e encontra um vaso sanitário: Banheiro... onde põe isso? [Pergunta a si mesmo; imediatamente coloca no cenário da UTI Pediátrica. Volta a explorar a caixa]. Mais... [encontra uma embalagem de dispensador de detergente] Pegar álcool, aqui... é importante! Tchii... [simula colocar nas mãos, esfrega e coloca no cenário da UTI Pediátrica] (Bart, 9 anos)

Brincando, os irmãos construíram, destruíram e reconstruíram o cenário representativo do ambiente da terapia intensiva.

Charlie: Eu vou montar o hos-pi-tal! [retira da caixa o cenário, coloca sobre a bancada e observa] Qual era a brincadeira mesmo?

P: Vamos brincar de uma criança que foi visitar a irmã na UTI.

Charlie retira da caixa um martelo; começa a bater nas paredes do cenário, delicadamente] Eu tô refazendo a UTI... Refazendo... a UTI. (Charlie, 7 anos)

Alguns brinquedos disponíveis na caixa, quando encontrados, permitiram aos irmãos, revelar suas preferências.

Charlie explora a caixa e encontra uma embalagem de sorvete: Isso! [em tom animado; pega a embalagem de sorvete da caixa] É uma caixa de sorvete! [fala com entusiasmo] 
Lola: Eu também gosto de sorvete, mas é de lego. [Pega a boneca princesa Elsa, aperta, fazendo-a tocar a música "Let it go"] Gosto dessa música "Lerisgou..." [cantarolando] Eu tenho um Olaf na minha casa... Eu não tenho a boneca... mas eu tenho o filme! E esse... "Lerisgou”! [referindo-se à música] (Charlie, 7 anos; Lola, 4 anos)

Durante o momento da brincadeira, os irmãos também fizeram considerações sobre a criança hospitalizada, perguntaram sobre ela e o hospital ser capaz de atender as suas necessidades.

Sitka conta à pesquisadora que o pai comprou um novo celular para Denahi: [...] Na verdade, meu pai já comprou, né, mas só que tá lá em casa. Por causa que é que... que ele falou assim, ó..., se aqui tem wi-fi... por causa que ele tá querendo mexer no wi-fi; por causa também... que ele é viciado nisso, né?! [...] Denahi é viciado nisso [wi-fi] Lá em casa ele não pára de mexer no celular... ele fica vin-te qua-tro ho-ras [enfatizando] mexendo nisso.. . Ele só parava assim, pra comer, beber água, assim... essas coisas... Aqui tem wi-fi? Ele [refere-se ao pai] não perguntou ainda, porque depois que quebrou não trouxe... [refere-se ao celular] (Sitka, 10 anos)

Os irmãos decidiram continuar a brincar ou finalizar a brincadeira mesmo sabendo do tempo combinado da sessão de BT.

$\mathrm{P}:$ Elroy, a gente vai ter que guardar os brinquedos, porque, ó, o ponteirinho do relógio já está na hora certa. [mostra o relógio e a indicação do ponteiro no horário combinado para o fim da brincadeira]

Elroy: Não tá! Eu tenho que brincar ainda... Eu não brinquei ainda... [e continua a brincadeira, ignorando o que a pesquisadora havia dito] (Elroy, 3 anos)

\section{DISCUSSÃO}

A maneira que a criança pode expressar os significados de sua experiência vivida se dá por meio do brincar ${ }^{20}$. Logo, ao aceitar o convite para brincar, os irmãos puderam significar sua confiança no ambiente de brincadeira, ou seja, reconheceram este ambiente como suficientemente bom, capaz de acolher o seu brincar. $\mathrm{O}$ ambiente suficientemente bom tem o caráter de possibilitar a entrada da criança no mundo real, colaborando para que ela diferencie a fantasia da realidade, integrando-se como ser numa unidade ${ }^{21}$.

Estudo sobre a dinâmica e a estrutura do BTD revelou que a sessão é processo com quatro etapas interdependentes e complementares. Aceitar o convite para brincar é parte da primeira etapa, nomeada como 'estabelecimento de vínculo', que ocorre de forma gradual, mas que é essencial para que a criança exponha sentimentos e emoções. Além disso, essa etapa apoia a próxima, 'explorando'25, movimento também observado nos irmãos das crianças hospitalizadas.

Os irmãos exploraram a caixa e os brinquedos observando, manuseando, perguntando, buscando descobrir e reconhecer o que estava disponível para brincar. Explorar é uma atividade que pertence à realidade externa; por meio dela, é possível entrar em contato com o que é real ${ }^{20}$.

Inicialmente, eles selecionaram elementos que remetiam à experiência da visita para brincar. Crianças com câncer trouxeram para a brincadeira o que consideraram de maior impacto em suas novas realidades, ou seja, o adoecimento e os procedimentos dolorosos, demonstrando dificuldades em extrapolar os momentos difíceis ${ }^{13}$.

Porém, os irmãos foram além do momento da visita. A sessão de BTD proporcionou a oportunidade de interessar-se por outros brinquedos da caixa, conforme a necessidade de conceber, como real, a experiência vivida, integrando-a ao "eu", o que pode favorecer sua jornada rumo ao amadurecimento ${ }^{16,17}$.

O BT, concebido como ambiente suficientemente bom, é capaz de promover a coragem dos irmãos em brincar a medida em que oferece suporte emocional, liberdade de expressão e experimentação, ponto de partida à experiência de novas descobertas e à concepção da realidade ${ }^{22,26}$.

Em algumas situações, os irmãos interessaram-se pela possibilidade do brinquedo realizar outra função. Nesse contexto, não se pode encarar as preferências e interesses dos irmãos de modo ingênuo, pois o momento do BT, desperta possibilidades para refletir, reagir e agir. O brincar não é apenas um ato espontâneo; ele facilita o acesso à atividade simbólica e a elaboração psíquica de vivências do cotidiano, tal como a experiência de visitar a criança hospitalizada. Assim, mais importante que o objeto brincado é a maneira como ele é usado e a relação que a criança estabelece com ele. Relacionar-se com o objeto, aqui representado pelo brinquedo, confere a ele a característica de ser reconhecido, pela criança, como real20.

Durante a brincadeira, os irmãos encontraram insumos médico-hospitalares e, diante deles, reconheceram sua função, identificando que não eram para brincar, o que pode significar o uso de seu repertório anterior a experiência da visita à criança hospitalizada, diferenciando esses insumos daqueles brinquedos que eles têm confiança e coragem para brincar, substituindo sua função inicial. No entanto, tal ato proibitivo junto a uma categoria de objetos pode indicar que a criança já conquistou a capacidade de simbolizar, uma vez que não há mais a necessidade de seu uso na brincadeira, porque ele já está nomeado, caracterizado e constituído na realidade vivida ${ }^{19}$

Brincar com insumos médico-hospitalares dramatizando procedimentos não é algo incomum para crianças que vivenciam o contexto da doença e da hospitalização. Trata-se de uma excelente oportunidade para compreender sentimentos como ansiedade, angústia, solidão e medo ${ }^{27,28}$.

Ao mesmo tempo em que há insumos hospitalares que foram nomeados, caracterizados e constituídos na realidade vivida, em algumas situações, os irmãos estabeleceram relação entre 
os brinquedos-personagens disponíveis na caixa e pessoas a sua volta, que fazem parte do seu cotidiano ou da experiência de visita. Tal inclusão pode indicar o jogo simbólico existente no próprio ato de brincar, na medida que há objetos externos à criança ${ }^{29}$, os quais nos diferentes momentos são escolhidos para ficar a parte da brincadeira para, em outro momento, surgir trazendo o contexto vivido, em especial, a visita hospitalar.

O jogo entre exterioridade e a internalização dos objetos que suscitam a visita à criança hospitalizada, mostra o brincar no espaço potencial ou transicional ${ }^{29}$. Esta não é área de compreensão consciente e reflexiva, mas de experimentação em que se alicerça o processo de simbolização, no qual os símbolos têm valor e existem enquanto tais. Assim, assegura-se o brincar como um recurso facilitador à atividade simbólica ${ }^{20} \mathrm{o}$ que pode contribuir para o significado dado pelos irmãos à experiência da visita. Observou-se comportamento semelhante em filhos de mulheres encarceradas que participaram de sessões de BTD ${ }^{14}$.

Os irmãos dramatizaram, na brincadeira, situações há algum tempo vividas, o que permite considerar que a sessão de BT dramático mobilizou lembranças e proporcionou um momento para representar o que foi significativo a eles. Lembrar é uma maneira de experienciar no presente o que já aconteceu no passado ${ }^{17}$. Por vezes, situações impactantes podem dificultar que a criança resgate a sua história no brincar. Crianças em tratamento oncológico demonstraram, ainda que brevemente, disposição para extrapolar às questões que envolvem o adoecimento, o que Ihes trouxe bem-estar ${ }^{13}$.

Os irmãos puderem usufruir da oportunidade para reviver momentos que lhe foram significativos, dramatizando a experiência de visita à criança hospitalizada, significando-a na continuidade do viver, sem que a experiência da doença seja determinante para a descontinuidade em seu processo de amadurecimento. À luz da teoria do amadurecimento, a origem da simbolização está na experiência com fenômenos e objetos transicionais, e sua conquista advém da diferenciação entre o que é interno e o que é externo, da distinção clara entre o que é fantasia e o que é fato, entre o que é criado e o que é encontrado, o que se dá no brincar ${ }^{16}$.

Nessa perspectiva é possível conceber que o BT dramático enquanto tecnologia de cuidado que promove o brincar ${ }^{9}$ é um mediador à atividade simbólica, uma vez que propicia a dimensão da transicionalidade, na qual é possível ter experiências e usar a criatividade ${ }^{19}$ para conceber a realidade.

Reviver as experiências na brincadeira representa o fazer (brincar) livre e criativo em consequência de uma situação e/ou do ambiente ${ }^{20}$. Traduz-se no movimento de encontrar a vida e os outros, ou seja, fazer a experiência de encontrar a realidade externa a partir de sua própria espontaneidade ${ }^{18}$.

Brincando, os irmãos recriaram o cenário da UTI Pediátrica, trazendo para esse ambiente, novos elementos, o que pode apontar que os irmãos significaram a visita como um espaço de uso da criatividade para desenvolver seu amadurecimento incorporando tal experiência a tarefa de concepção da realidade, já que quem é criativo pode trazer novos elementos à brincadeira e fazer nela. Na concepção winnicottiana, o fenômeno criativo é uma atividade de experimentação e está relacionada ao sentimento de realidade e não a uma ação ou ato inédito ${ }^{16}$.

Assim, ao viver criativamente o brincar, é possível ter um novo contato com a experiência, lançar sobre ela um novo olhar e, a partir de então, elaborar o que lhe foi significativo, contribuindo para que a experiência possa ser concebida como real ${ }^{16}$.

No entanto, a criatividade é uma ação que pressupõe destrutividade, ou seja, é preciso promover a destruição, na fantasia inconsciente, do que é subjetivo para conceber o que é objetivo, real ${ }^{17,19}$. Esse movimento pôde ser percebido quando os irmãos construíram, destruíram e reconstruíram o cenário representativo do ambiente da terapia intensiva, o que novamente corrobora com a significação da experiência de visita como um momento de integração da realidade e não de ruptura.

Quando a criança vive o brincar de todas as formas possíveis, ela constrói o contato com a realidade e experiencia a continuidade de ser $^{17}$. Proporcionar um ambiente de brincadeira que permite aos irmãos deixar fruir sua criatividade e a experiência vivida por meio dela, são o princípio para que eles concebam a continuidade de sua existência. Só é possível ter o sentimento de continuar a ser quem tem o sentimento de existir ${ }^{17,18}$.

Assim, quando os irmãos, durante a brincadeira revelam suas preferências, significam a visita, distinguindo-se dela, porque se reconhecem como um "eu", separado de um "não-eu", pois somente quem existe é capaz de perceber a si e ao mundo ${ }^{16}$. Essa capacidade também se revela quando os irmãos fazem considerações sobre a criança hospitalizada, e significam a visita como momento de expressar preocupação com o atendimento das necessidades da criança hospitalizada no hospital.

Ter a consciência de ser "si-mesmo", é uma capacidade a ser conquistada na jornada do amadurecimento, o que envolve a relação entre a singularidade do "eu" e o encontro com "o outro" ("não-eu") e a consequente integração das novas experiências, como a da visita na UTI Pediátrica. "Eu sou, eu existo, adquiro experiências, enriqueço-me e tenho uma interação introjetiva e projetiva com o "não-eu", o mundo real da realidade compartilhada"16:60.

O movimento de fazer por si mesmo pode ser percebido quando decidem continuar brincando ou interromper a brincadeira e significou que a visita hospitalar é uma experiência que reforça o senso de "si-mesmo", que os leva a fazer por eles mesmos a escolha de finalizar ou continuar na brincadeira.

O sentimento de existir deve ser mantido durante toda a vida, contudo continuar a ser, mesmo diante das adversidades, é um grande desafio. Agindo conforme sua vontade, independentemente dos limites do ambiente, os irmãos se impuseram enquanto ser que existe. Essa capacidade que o irmão tem corresponde a um estado emocional saudável e revela o viver criativo de quem tem a liberdade de ser e fazer, de quem percebe a si, o outro e o mundo, de quem tem o "sentimento de existir" e de "ser"18.

O modo criativo de viver resulta em ações livres e espontâneas diante das circunstâncias da vida, dando suporte para que o indivíduo mantenha o sentimento de ser "si-mesmo" 
nas interações com o mundo. A essas ações, dá-se o nome de "gesto espontâneo", que é uma das muitas maneiras pela qual o verdadeiro "eu" pode se expressar. Ele representa a autenticidade e a genuinidade própria de cada um. Por meio de ações genuínas a criança pode usufruir das experiências da vida, sem medo do aniquilamento, e, assim, continuar a ser ${ }^{16}$.

O brincar proporcionado pelo enfermeiro pôde favorecer aos irmãos viver criativamente significando suas experiências, como a da visita à criança hospitalizada, possibilitando que essas sejam concebidas como real e integradas ao "eu". Pelo brincar o irmão significou, por meio dos sentimentos expressos nos resultados, que a vida é real, que vale ser vivida e que é possível continuar a ser mesmo diante das dificuldades que possam se apresentar.

\section{CONCLUSÃO E IMPLICAÇÕES PARA A PRÁTICA}

O BTD possibilitou o brincar que, compreendido à luz da teoria do amadurecimento, revelou que o irmão significou a visita como uma experiência de integração do "eu", na medida em que eles incorporaram a visita às brincadeiras, além de revelarem emoções, desejos e preferências do cotidiano, mobilizaram lembranças de situações vividas, mostraram a capacidade de destruir e reconstruir o objeto, a fim de constituir a realidade de maneira criativa, demonstrando o sentimento de continuar a ser nas interações com o mundo, o que revela o viver criativo daquele que é "si-mesmo".

A visita parece não ter significado, aos irmãos deste estudo, uma experiência traumática, capaz de interferir ou interromper a continuidade de ser, pois foram capazes de significar as situações adversas, demonstrando confiança, coragem e substituindo a função original do brinquedo por outra que respondesse a sua necessidade de comunicar-se e constituir a realidade. Tal capacidade de significação foi possível a partir da implantação de linguagem adequada a eles e a oferta da oportunidade de promover a elaboração da experiência da hospitalização, que nesse estudo foi desenvolvida pelo BTD.

Vale destacar que esse estudo demonstra ao enfermeiro a necessidade cuidar do irmão, considerando-o como parte da família da criança hospitalizada, incluindo-o no contexto da hospitalização, o que não implica em apenas permitir a visitação, mas também compreender o que a visita significa para eles. Para tanto, recomenda-se a organização de um ambiente favorável de brincadeira, caracterizado pelo brincar livre, não dirigido, em que o enfermeiro tenha uma postura que acolhe e suporta a brincadeira, sem julgamentos ou inferências, para que o irmão conceba a realidade mediada pelo espaço potencial, a fim de simbolizar a experiência vivida, como ocorrido no presente trabalho.

No que diz respeito às limitações do estudo, a intervenção com BTD mostrou-se relevante para compreender a experiência dos irmãos, mas pode não ser suficiente para promover mudanças nas políticas de visitação por representar um seleto grupo de participantes, embora possam suscitar discussões e reflexões relevantes.
Este estudo trouxe a importância de, no cuidado à família, vislumbrar o irmão da criança hospitalizada, compreendendo que esse cuidado é caracterizado como a possibilidade de significação da experiência vivida e, assim, recomenda-se a adoção de uma proposta teórica para a leitura da experiência da visita, quando admitido o uso do BT ao irmão da criança hospitalizada.

\section{FINANCIAMENTO}

"O presente trabalho foi realizado com apoio da Coordenação de Aperfeiçoamento de Pessoal de Nível Superior-Brasil (CAPES) - Código de Financiamento 001, Bolsa de Doutorado concedida a Glicinia Elaine Rosilho Pedroso), Processo no 38P-4071/2019.

\section{CONTRIBUIÇÕES DOS AUTORES}

Desenho do estudo. Glicinia Elaine Rosilho Pedroso. Ana Paula Rigon Francischetti Garcia. Luciana de Lione Melo. Coleta ou produção dos dados. Glicinia Elaine Rosilho Pedroso. Análise de dados. Glicinia Elaine Rosilho Pedroso. Ana Paula Rigon Francischetti Garcia. Luciana de Lione Melo.

Interpretação dos resultados. Glicinia Elaine Rosilho Pedroso. Ana Paula Rigon Francischetti Garcia. Luciana de Lione Melo.

Redação e revisão crítica do manuscrito. Glicinia Elaine Rosilho Pedroso. Ana Paula Rigon Francischetti Garcia. Luciana de Lione Melo.

Aprovação da versão final do artigo. Glicinia Elaine Rosilho Pedroso. Ana Paula Rigon Francischetti Garcia. Luciana de Lione Melo.

Responsabilidade por todos os aspectos do conteúdo e a integridade do artigo publicado. Glicinia Elaine Rosilho Pedroso. Ana Paula Rigon Francischetti Garcia. Luciana de Lione Melo.

\section{EDITOR ASSOCIADO}

Aline Cristiane Cavachilli Okido (1)

\section{EDITOR CIENTÍFICO}

Ivone Evangelista Cabral ()

\section{REFERÊNCIAS}

1. Jacob M, Horton C, Rance-Ashley S, Field T, Patterson R, Johnson $C$ et al. Family members in an Intensive Care Unit with continuous visitation. Am J Crit Care. 2016;25(2):118-25. http://dx.doi.org/10.4037/ ajcc2016258. PMid:26932913.

2. Ministério da Saúde (BR). Atenção humanizada ao recém-nascido. Método Canguru: manual técnico. $2^{\mathrm{a}}$ ed. Brasília: Ministério da Saúde; 2017.

3. Rodriguez C, Mathew S. Time to change: from families as visitors to families as partners in care. Can J Crit Care Nurs [Internet]. 2016 [citado 2020 dez 23];27(2):42. Disponível em: https://web.a.ebscohost.com/abstract?direc$\mathrm{t}=$ true\&profile=ehost\&scope=site\&authtype=crawler\&jrnl=23688653\&AN $=$ 115902266\&h=c9zon839lvdYUhNeuRKaDejlkfIFLNC7lgv6ns\%2fpEGNWzO26vcuAPwYNgT2hRtHBAc0JJyJOY\%2b2dn24hFUFRvw\%3d\%3d\&crl=c\&resultNs=AdminWebAuth\&resultLocal=ErrCrINotAuth\&crlhashurl=login aspx\%3fdirect\%3dtrue\%26profile\%3dehost\%26scope\%3dsite\%26authtype\%3dcrawler\%26jrnl\%3d23688653\%26AN\%3d115902266 
4. Gill MA. Making space for siblings in family-centered care. Pediatr Nurs [Internet]. 2020 [citado $2020 \mathrm{dez}$ 18];46(1):48-51. Disponível em: https:// www.proquest.com/openview/dfdf015cc6db379be949a2b72be8d748 $/ 1$ ?pq-origsite $=$ gscholar $\& \mathrm{cbl}=47659$

5. Resolução no 41, de 13 de outubro de 1995 (BR). Aprova em sua íntegra o texto oriundo da Sociedade Brasileira de Pediatria, relativo aos Direitos da Criança e do Adolescente hospitalizados. Diário Oficial da União, Brasília (DF), 17 out 1995: Seção 1: 163/9-16320.

6. Olivier-D'Avignon M, Dumont S, Valois P, Cohen S. The needs of siblings of children with a life-threatening illness, part 1: conceptualization and development of a measure. Palliat Support Care. 2017;15(6):644-64. http://dx.doi.org/10.1017/S1478951516001127. PMid:28122656.

7. Terp K, Sjöström-Strand A. Parents' experiences and the effect on the family two years after their child was admitted to a PICU-An interview study. Intensive Crit Care Nurs. 2017;43:143-8. http://dx.doi.org/10.1016/j. iccn.2017.06.003. PMid:28663106.

8. Sousa R No, Tarabay CH, Lourenço MTC. Reflexões sobre a visita da criança durante a hospitalização de um ente querido na UTI adulto. Rev SBPH. [Internet]. 2017 [citado 2021 jun 15];20(1):5-16. Disponível em: http://pepsic.bvsalud.org/scielo.php?script=sci_arttext\&pid=S151608582017000100002\&lng=pt

9. Melo LL, Maia EBS, Luz JH, Souza MA, Ribeiro CA. Brinquedo terapêutico: tecnologia de cuidado à criança. In: Souza AlJ, organizador. Enfermagem Pediátrica: avanços e contribuições para a prática clínica. Florianópolis: Papa-Livro; 2021. p. 217-40.

10. Maia EBS, Ohara CVS, Ribeiro CA. Ensino do brinquedo terapêutico na graduação em enfermagem: ações e estratégias didáticas utilizadas por professores. Texto Contexto Enferm. 2019;28:e20170364. http:// dx.doi.org/10.1590/1980-265x-tce-2017-0364.

11. Resolução $n^{\circ}$ 546, de 9 de maio de 2017 (BR). Atualiza norma para utilização da técnica do Brinquedo/Brinquedo Terapêutico pela Equipe de Enfermagem na assistência à criança hospitalizada. Diário Oficial da União [periódico na internet], Brasília (DF), 17 Maio 2017: Seção 1: 93 [citado 2020 dez 21]. Disponível em: http://www.cofen.gov.br/ wp-content/uploads/2017/05/Resolu\%C3\%A7\%C3\%A30-546-17.pdf

12. Silva SGT, Santos MA, Floriano CMF, Damião EBC, Campos FV, Rossato LM. Influence of therapeutic play on the anxiety of hospitalized school-age children: clinical trial. Rev Bras Enferm. 2017;70(6):1244-9. http://dx.doi.org/10.1590/0034-7167-2016-0353. PMid:29160486.

13. Fonseca MRA, Campos CJG, Ribeiro CA, Toledo VP, Melo LL. Revealing the world of oncological treatment through dramatic therapeutic play. Texto Contexto Enferm. 2015;24(4):1112-20. http://dx.doi.org/10.1590/01040707201500003350014

14. Melo LL, Ribeiro CA. Growing up (being) without a mother: children's experiences during maternal imprisonment. Rev Bras Enferm.
2020;73(Suppl 4):e20200413. http://dx.doi.org/10.1590/0034-71672020-0413. PMid:33206855.

15. Martins J, Bicudo MAV. A pesquisa qualitativa em psicologia: fundamentos e recursos básicos. São Paulo: Moraes; 2005.

16. Winnicott DW. O ambiente e os processos de maturação: estudos sobre a teoria do desenvolvimento emocional. Porto Alegre: Artes Médicas; 1983.

17. Dias EO. A teoria do amadurecimento de D. W. Winnicott. 3. ed. São Paulo: DWW; 2017.

18. Belo F, Scodeler K. A importância do brincar em Winnicot e Schiller. Tempo Psicanal. [Internet]. 2013 [citado 2021 jun 17];45(1):91-101. Disponível em: http://pepsic.bvsalud.org/scielo.php?script=sci_arttext\&pid=S0101. 48382013000100007\&lng=pt

19. Winnicott DW. A criança e o seu mundo. Rio de Janeiro: LTC; 2015

20. Winnicott DW. O brincar e a realidade. Rio de Janeiro: LTC; 1975.

21. Winnicott DW. Os bebês e suas mães. São Paulo; Martins Fontes; 1994

22. Maia EB, Melo LL, La Banca RO. O brinquedo terapêutico na assistência de enfermagem. In: Collet N, Toso BRGO, Vieira CS. Manual de enfermagem em pediatria. Goiânia: AB; 2020. p. 49-61.

23. Giorgi A. Difficulties encountered in the application of the phenomenologica method in the social sciences. Anal Psicol. 2006;24(3):353-61. http:// dx.doi.org/10.14417/ap. 175 .

24. van Rijnsoever FJ. I can't get no saturation: a simulation and guidelines for sample sizes in qualitative research. PLoS One. 2017:12(7):e0181689. http://dx.doi.org/10.1371/journal.pone.0181689. PMid:28746358.

25. Santos VLA, Almeida FA, Ceribelli K, Ribeiro CA. Understanding the dramatic therapeutic play session: a contribution to pediatric nursing. Rev Bras Enferm. 2020;73(4):e20180812. http://dx.doi.org/10.1590/00347167-2018-0812. PMid:32520094.

26. Melo LL, Pedroso GER, Garcia APRF. O brincar de irmãos de crianças hospitalizadas após visita hospitalar. Rev enferm UFPE on line. 2019:13:e240898. https://doi.org/10.5205/1981-8963.2019.240898.

27. Coelho HP, Souza GSD, Freitas VHS, Santos IRA, Ribeiro CA, Sales JKD et al. Percepção da criança hospitalizada acerca do brinquedo terapêutico instrucional na terapia intravenosa. Esc Anna Nery. 2021;25(3):e20200353. http://dx.doi.org/10.1590/2177-9465ean-2020-0353.

28. Caleffi CCF, Rocha PK, Anders JC, Souza AIJ, Burciaga VB, Serapião LS. Contribuição do brinquedo terapêutico estruturado em um modelo de cuidado de enfermagem para crianças hospitalizadas. Rev Gaúcha Enferm. 2016;37(2):e58131. http://dx.doi.org/10.1590/19831447.2016.02.58131. PMid:27253598.

29. Fulgencio L. A constituição do símbolo e o processo analítico. Paidéia 2011;21(50):393-401. http://dx.doi.org/10.1590/S0103-863X2011000300012. 